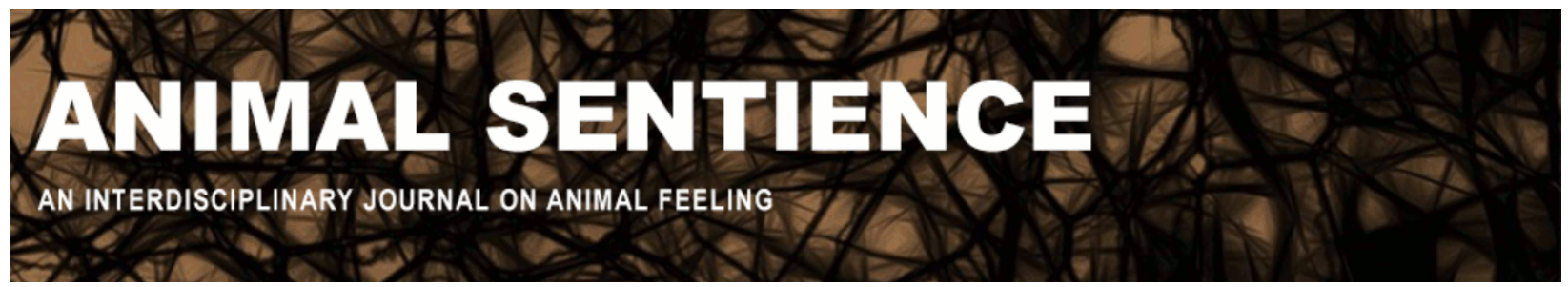

Soryl, Asher (2020) Invertebrate welfare in the wild. Animal Sentience 29(7) DOI: $10.51291 / 2377-7478.1588$

Date of submission: $2020-06-12$

Date of acceptance: 2020-06-15

(c) (i)




\title{
Invertebrate welfare in the wild
}

Commentary on Mikhalevich \& Powell on Invertebrate Minds

\author{
Asher Soryl \\ Bioethics Centre, University of Otago
}

\begin{abstract}
Mikhalevich \& Powell argue that certain cognitive-affective biases might distort people's consideration of invertebrate minds and that the moral risks of false negatives in sentience research deserve greater consideration under precautionary frameworks. In this commentary, I draw comparisons between biases that concern wild animals and conditions in nature, arguing that the moral risks of disregarding the possible mental welfare of invertebrates are compounded by facts about their lives in the wild.
\end{abstract}

Asher Soryl is a Ph.D candidate researching the proposed discipline Welfare Biology at the University of Otago Bioethics Centre. Website

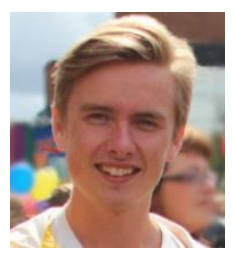

In their target article, Mikhalevich \& Powell (2020) (M\&P) highlight important considerations concerning the possible mental welfare of invertebrates, who have previously been neglected in the ethical and scientific literature. M\&P's arguments touch on two main points related to the interpretation of research on the mental states of these animals: (1) people are subject to a number of affective biases reducing their ability to perceive the scientific and ethical significance of this research; and (2) the moral risks that come with ignoring the possible mental welfare of invertebrates have been improperly addressed. I also discuss the following related points: (1a) affective biases distort people's views of wild animals, leading them to ignore certain facts about their lives; and (2a) these facts compound the moral risks that arise from disregarding their potential mental welfare.

Biases Against Wild Invertebrates. M\&P present evidence of cognitive-affective biases which shape our beliefs and judgements on invertebrate minds. These biases parallel commonly accepted views about nature and the lives of wild animals. For example, people's interest in and aesthetic appreciation of wild animals are correlated with how much they resemble humans in their biology, morphology, and behaviour (Burghardt and Herzog 1980; Kellert 1985; Batt 2009). It is also common to think of nature as an idyllic place where there is a natural "order" or a "balance" of states, ignoring other facts about it that are considered less interesting or distasteful (Kellert 1991; Burton 2015; Waldhorn 2019). These biases are recognised across disciplines and levels of education; however, they are do not reflect actual circumstances in nature, nor relations between wild animals and ecological processes (Sterelny and Griffiths 1999; Cuddington 2001; Horta 2010). In addition, they might lead one to downplay or underestimate the significance of the following two important facts about nature:

(1) All animals reproduce in excess of the carrying capacity of their environments; only one child per parent must survive and reproduce for a population to remain stable over time. Invertebrates are among the most fecund animals, sometimes reproducing in the tens to hundreds of thousands of offspring per clutch (Hapgood 1979; Solbrig and Solbrig 1979; 
Brueland 1995). A consequence of these facts is that most invertebrate animals who come into existence are likely to die before maturing, usually as infants (Horta 2015; Tomasik 2015; Soryl 2018). This suggests that the welfare of most invertebrates coming into existence might be negative at the time of their deaths, and possibly also throughout their short lives. ${ }^{1}$

(2) M\&P state that "Invertebrate brains comprise upwards of $99 \%$ of the brains that exist on Earth". Even if we only consider terrestrial arthropods - a certain subset of invertebrates that have been researched for possibly having minds - preliminary estimates place their numbers in the range of $10^{17}$ to $10^{19}$ (Tomasik 2018). Compared to how many mammals and birds are estimated to exist (between $10^{11}$ to $10^{12}$ ), there may be as many as one hundred thousand to one hundred million times as many terrestrial arthropods in the world at any given point. ${ }^{2}$

Compounded Moral Risks. These two facts about the reproduction and estimated numbers of extant invertebrates have potentially dire consequences for their welfare if they are sentient beings. M\&P consider Birch's (2017) Animal Sentience Precautionary Principle as a possible approach to managing this uncertainty. They discuss three key areas where the framework might be improved: (1) The assumption that sentience can always be inferred by homological inference within a given order should be defended. (2) The evidential threshold for precaution should be expanded to avoid cases of underdetermination. (3) Moral risks should be considered more closely alongside empirical evidence given the high costs of false negatives. This final point is relevant to the facts discussed above about the lives of wild invertebrates.

Given the sheer quantity of extant wild invertebrates, I propose that the moral risks of denying the possibility of their mental welfare might render negative empirical results insignificant for ethical and policy-based considerations about them. ${ }^{3}$ This is because the costs of finding false negatives are extremely high even if we did have the capacity to test for sentience throughout the animal kingdom. Indeed, this cost might be many times greater than M\&P posit given how many wild invertebrates are likely to exist at any one time. For example, let us assume that there is only a 0.01 likelihood that terrestrial arthropods have a mental welfare, and if they do, that their moral standing is only 0.01 compared to the full moral standing of a regular mammal or bird (which is 1 ). Assuming the conservative ranges in footnote 2, the case for considering terrestrial arthropods is ten times more than the case for considering mammals and birds. Assuming the generous ranges in footnote 2, the case for considering terrestrial arthropods is ten thousand times more than the case for considering mammals and birds. ${ }^{4}$

The above estimates assume many variables which I have not argued for; however, it does highlight the potential scope of the moral risks M\&P mention in passing. How these risks should be managed in practice is beyond the scope of this commentary, although it reduces the viability of the "overgeneralization has moral costs" rebuttal against taking moral risks seriously (M\&P, p. 18).

\footnotetext{
${ }^{1}$ Assuming that these animals have a mental welfare to begin with.

$210^{12} / 10^{17}=0.00001$

$10^{11} / 10^{19}=0.00000001$

${ }^{3}$ Assuming that their negative welfare is morally considerable to begin with, which has previously been defended: see Hadley 2006; Horta 2013; Faria 2016; and Knutsson and Munthe 2017.

${ }^{4}\left(\left(0.01 \times 10^{17}\right) \times 0.01\right) / 10^{12}=10$

$\left(\left(0.01 \times 10^{19}\right) \times 0.01\right) / 10^{11}=10,000$
} 


\section{References}

Batt, S. 2009. Human attitudes towards animals in relation to species similarity to humans: A multivariate approach. Bioscience Horizons, 2 (2), 180-190.

Birch, J. 2017. Animal sentience and the precautionary principle. Animal Sentience 16(1).

Brueland, H. 1995. Highest lifetime fecundity. In: University of Florida Book of Insect Records, 41-45.

Burghardt, G.M. and Herzog, H.A., 1980. Beyond conspecifics: Is Brer Rabbit our brother?. BioScience, 30 (11), 6.

Burton, T. 2015. Review of Research on Public Perceptions of Naturalness. Nuffield Council on Bioethics.

Cuddington, K. 2001. The "balance of nature" metaphor and equilibrium in population ecology. Biology \& Philosophy, 16 (4), 463-479.

Faria, C. 2016. Animal Ethics Goes Wild: The Problem of Wild Animal Suffering and Intervention in Nature. Universitat Pompeu Fabra, Barcelona.

Hadley, J. 2006. The duty to aid nonhuman animals in dire need. Journal of Applied Philosophy, 23 (4), 445-451.

Hapgood, F. 1979. Why Males Exist, An Inquiry into the Evolution of Sex. New York: Morrow.

Horta, O. 2010. Debunking the idyllic view of natural processes: Population dynamics and suffering in the wild. Revista Iberoamericana de Estudios Utilitaristas, 17 (1), 73-90.

Horta, O. 2013. Zoopolis, intervention, and the state of nature. Law, Ethics, and Philosophy, 1, 113-125.

Horta, O. 2015. The problem of evil in nature: Evolutionary bases of the prevalence of disvalue. Relations, 3 (2), 17-32.

Kellert, S.R. 1985. American attitudes toward and knowledge of animals: An update. In: M.W. Fox and L.D. Mickley, eds., Advances in Animal Welfare Science 1984. Dordrecht: Springer Netherlands, 177-213.

Kellert, S.R. 1991. Japanese perceptions of wildlife. Conservation Biology, 5 (3), 297-308.

Knutsson, S. and Munthe, C. 2017. A virtue of precaution regarding the moral status of animals with uncertain sentience. Journal of Agricultural and Environmental Ethics, 30 (2), 213-224.

Mikhalevich, I. and Powell, R. 2020. Minds without spines: Evolutionarily inclusive animal ethics. Animal Sentience 29(1).

Solbrig, O.T. and Solbrig, D.J. 1979. Introduction to Population Biology \& Evolution. London: Addison-Wesley.

Soryl, A. 2018. Establishing the Moral Significance of Wild Animal Welfare and Considering Practical Methods of Intervention. University of Amsterdam.

Sterelny, K. and Griffiths, P. 1999. Sex and Death: An Introduction to Philosophy of Biology. Chicago: University of Chicago Press.

Tomasik, B. 2015. The importance of wild-animal suffering. Relations, 3 (2), 133-152.

Tomasik, B. 2018. How many wild animals are there?. Reducing Suffering.

Waldhorn, D.R. 2019. Toward a new framework for understanding human-wild animal relations. American Behavioral Scientist, 000276421983046. 


\section{$\$$ Summer School 2020 INNOVATIVE SCIENCE WITHOUT ANIMALS}

\section{June 22-26, 2020}

\section{Online Virtual Conference}

\section{Calling all students and early-career researchers!}

Join us for a FREE conference on innovative approaches in toxicology and biomedical sciences!

\section{This event features:}

- Lecture sessions about modern alternatives to the use of animals in toxicology and biomedical sciences

- Virtual laboratory tours

E-poster presentations

- Virtual engagement with speakers and attendees

Deadline to apply for the full program is June 10. Registration for individual lectures is available.

For more information visit InnovativeScience2020.org

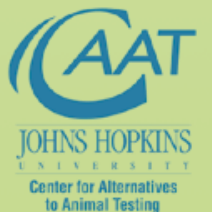

Physicians Center for Alternatives
to Animal Testing

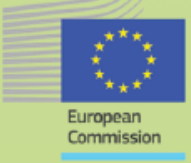

